\title{
Analysis of Output Voltage Harmonics of Voltage Source Inverter used PI and PID Controllers Optimized with ITAE Performance Criteria
}

\author{
Ozan Gül $1^{1, *}$, and Nusret Tan ${ }^{2}$ \\ ${ }^{1}$ Bingol University, Department of Electrical and Electronics Engineering, Bingol, Turkey \\ ${ }^{2}$ Inonu University, Department of Electrical and Electronics Engineering, Malatya, Turkey
}

\begin{abstract}
In this article, PI and PID controllers are designed using ITAE (Integral Time Absolute Error) Performance Criteria in order to obtain the controller parameters assuring improved response at selected load. The voltage source inverter (VSI) including PI and PID controllers whose parameters are estimated by minimizing errors using ITAE performance criteria are modeled in MATLAB environment. The stability analysis of the control system will be presented. VSI controlled with the PI-ITAE and the PID-ITAE controller are simulated for various loads and the results are analyzed using FFT analysis for observing and comparing the total harmonic distortion (THD) of the output voltage. The quality of the sinusoidal waveform is more important than the quantity and in order to achieve that, we need to reduce the harmonic content in the output.
\end{abstract}

\section{Introduction}

Minimization of the total harmonic distortion (THD) at the output of an inverter is essential to obtain a pure sinusoidal wave. Various methods and strategies to obtain püre sinusoidal voltage or current waveforms at the output of a DC/AC inverter [1-4], are intensely studied with the aim of eliminating dominant harmonics. Conventional proportional-integral (PI) and proportional-integral-derivative (PID) controllers that are widely used in the voltage source inverter (VSI) can reduce such harmonic distortion when operated with nonlinear or periodic loads, the output voltage of these systems contains significant harmonic distortion. In PI and PID controllers design, an optimization algorithm is commonly employed to search for the optimal controller parameters. The most commonly used functions are the time domain integral error performance criteria [2], which are based on calculating the error signal between the system output and the input reference signal. In this study, the VSI including PI and PID controller whose parameters are estimated by minimizing errors using integral of time multiplied by absolute error (ITAE) performance criteria are simulated in MATLAB simulink for resistive loads and nonliner loads and the results are analyzed for observing the total harmonic distortion

* Corresponding author: ogul@bingol.edu.tr 
(THD) of the output voltage. The comparison of the PI-ITAE and the PID- ITAE, is presented by taking into consideration the THD at the inverter output voltage under the same conditions for different types of loads.

\section{Minimum error integral criteria tuning methods}

The shape of the complete closed loop response, from time $t=0$, until steady state has been reached, could be used for the formulation of a dynamic performance criterion. Unlike the simple criteria of this category are based on the entire response of the process .

The most often used are,

Integral of the Time -Weighted Absolute Error (ITAE) where

$$
\operatorname{ITAE}=\int_{0}^{\infty} t \cdot|e(t)| \cdot d t
$$

Integral of the Absolute Error (IAE) where

$$
I A E=\int_{0}^{\infty}|e(t)| \cdot d t
$$

Integral of the Square Error (ISE) where

$$
I S E=\int_{0}^{\infty} e(t)^{2} \cdot d t
$$

Integral of the Time-Weighted Square Error or Mean Square Error (MSE) where

$$
M S E=\int_{0}^{\infty} t \cdot e(t)^{2} \cdot d t
$$

Where $\mathrm{e}(\mathrm{t})=\mathrm{Ysp}(\mathrm{t})-\mathrm{Y}(\mathrm{t})$ is the deviation (error) of the response from the desired set point.

\section{Design of controller}

\subsection{Voltage source of inverter (VSI)}

A single phase full-bridge inverter shown in Fig.1 [4]

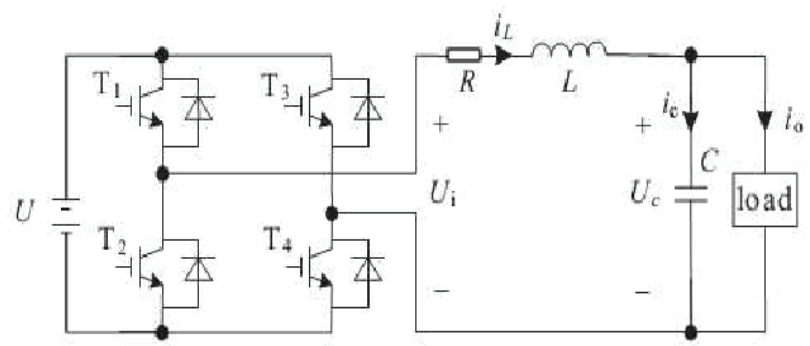

Fig. 1. Single phase voltage source inverter

By applying KVL and KCL (9), 


$$
\begin{gathered}
\frac{d v_{C}}{d t}=\frac{1}{C} i_{L}-\frac{1}{C} i_{o} \\
\frac{d i_{L}}{d t}=\frac{1}{L} v_{i}-\frac{1}{L} v_{C}-\frac{R}{L} i_{L}
\end{gathered}
$$

The inverter transfer function with no load can be derived from above equations as,

$$
P(s)=\frac{U_{C}(s)}{U_{i}(s)}=\frac{1}{\mathrm{LC} s^{2}+R C s+1}
$$

where, $\mathrm{U}_{\mathrm{c}}$ is the voltage of filter capacitance $\mathrm{C}$ and $\mathrm{U}_{\mathrm{i}}$ is the inverter bridge output voltage. By putting values , $L=0.552 \mathrm{mH}, R=0.3 \Omega, C=140 \mu F$, the transfer function of VSI is found as;

$$
P(s)=\frac{1}{77.28 * 10^{-9} s^{2}+42 * 10^{-6} s+1}
$$

\subsection{Optimization with ITAE performance criteria for PI and PID controller}

$\mathrm{Kp}, \mathrm{Ki}, \mathrm{Kd}$ values of PI and PID controls designed using ITAE performance criterion for VSI system are shown in Table 1.

Table 1. Kp, Ki, Kd values of PI-ITAE and PID-ITAE controller

\begin{tabular}{|c|c|c|c|c|}
\hline & $\mathbf{K p}$ & $\mathbf{K i}$ & $\mathbf{K d}$ & $\mathbf{I T A E}$ \\
\hline PID & 1,69 & 3,13 & 0,002 & 0,5931 \\
\hline PI & 10 & 1110 & ------ & 0,022804 \\
\hline
\end{tabular}

\section{Result and conclusion}

A MATLAB simulation is carried out for VSI controlled with the PI-ITAE and the PIDITAE controller for observing the total harmonic distortion (THD) of the output voltage. To demonstrate the advantages, the PI-ITAE and the PID-ITAE are applied to the same VSI for comparative purposes. The tracking performance is tested with both the resistive load and the nonlinear load. Simulation results are given in Table 2.

Table 2. THD output of voltage under different values of resistive and nonlinear loads

\begin{tabular}{|c|c|c|l|l|l|l|l|}
\hline & & $\begin{array}{l}\text { R (50k } \\
\text { Watt) }\end{array}$ & $\begin{array}{l}\text { R (100k } \\
\text { Watt) }\end{array}$ & $\begin{array}{l}\text { R (150k } \\
\text { Watt) }\end{array}$ & $\begin{array}{l}\text { RLC(50 } \\
\text { k Watt, } \\
\text { 5k Var, } \\
\text { 5k Var) }\end{array}$ & $\begin{array}{l}\text { RLC(100 } \\
\text { k Watt, } \\
\text { 10k Var, } \\
\text { 10k Var) }\end{array}$ & $\begin{array}{l}\text { RLC(150 } \\
\text { k Watt, } \\
\text { 15k Var, } \\
\text { 15k Var) }\end{array}$ \\
\hline PI & THD(\%) & 6.57 & 5.64 & 5.69 & 5.01 & 4.14 & 4.55 \\
\hline PID & THD(\%) & 7.17 & 7.22 & 7.5 & 2.79 & 3.23 & 4.05 \\
\hline
\end{tabular}


In Matlab Simulink, a network is created, VSI is used with voltage of $440 \mathrm{~V}$, frequency of $50 \mathrm{~Hz}$, the RLC filter having the value of $\mathrm{L}=0.552 \mathrm{mH}, \mathrm{C}=140 \mu \mathrm{F}, \mathrm{R}=0.3 \Omega$.

From the simulation results, it can be found that resistive loads cause high THD value both systems. PID-ITAE system show better THD restraint under lighter load. The PID-ITAE control will improve the THD performance of the system for nonlinear loads, but PI-ITAE control is better for resistive load.

\section{References}

1. L. Guo, J. Y. Hung, R. M. Nelms, Proc. IEEE Appl. Power Electron. Conf. 383. (2002)

2. D. Maiti, A. Acharya, M. Chakraborty, A. Konar, R. Janarthanan, ICIAFs, 457. (2008)

3. B. Husodo, S. Ayop, ICCAIE, (2011)

4. P. C. Buchade, V. A. Vyawahare, V. V. Bhole, CSCITA, (2014) 